\title{
Cervical Bronchogenic Cysts Mimicking Papillary Thyroid Carcinoma on Ultrasound
}

\author{
Dongbin $\mathrm{Ahn}^{1}\left(\mathbb{D}\right.$ and Jeong Kyu Kim ${ }^{2}$ \\ ${ }^{1}$ Department of Otolaryngology-Head and Neck Surgery, School of Medicine, Kyungpook National University, Daegu; and \\ ${ }^{2}$ Department of Otolaryngology-Head and Neck Surgery, School of Medicine, Catholic University of Daegu, Daegu, Korea
}

\section{초음파 검사상 갑상선 유두암 소견을 보인 경부 기관지원성 낭종}

안 동 빈 · 김 정 규

경북대학교 의과대학 이비인후-두경부외과학교실, ${ }^{1}$ 대구가톨릭대학교 의과대학 이비인후-두경부외과학교실 ${ }^{2}$

\author{
Received February 1, 2019 \\ Revised March 25, 2019 \\ Accepted March 27, 2019 \\ Address for correspondence \\ Dongbin Ahn, MD \\ Department of Otolaryngology- \\ Head and Neck Surgery, \\ School of Medicine, \\ Kyungpook National University, \\ 130 Dongdeok-ro, Jung-gu, \\ Daegu 41944, Korea \\ Tel $+82-53-200-5781$ \\ Fax $+82-53-200-4524$ \\ E-mail godlikeu@naver.com
}

Here, we describe two cases of cervical bronchogenic cysts mimicking thyroid cancer on ultrasound (US), introducing some sources of diagnostic error with the aim of improving the understanding of cervical bronchogenic cysts. In these cases, US demonstrated ill-defined nonhomogeneous hypoechoic nodules at the inferior pole of the thyroid gland, exhibiting several echogenic foci that mimicked microcalcification of papillary thyroid carcinoma. Although cervical bronchogenic cysts can be presented as highly suspicious thyroid nodules on US, recognition of this disease entity and comprehensive understanding of its presentation can allow an appropriate diagnostic process without unnecessary diagnostic surgery.

Korean J Otorhinolaryngol-Head Neck Surg 2019;62(12):735-9

Key Words Bronchogenic cyst · Diagnosis · Papillary thyroid carcinoma - Thyroid nodule.

\section{Introduction}

Thyroid nodules are found in up to $50 \%$ of the adult population on routine ultrasound (US) examination. ${ }^{1,2)}$ For the evaluation of thyroid nodules, high-resolution US, with or without US-guided fine-needle aspiration cytology (FNAC), has been commonly used and is acknowledged as the first-line imaging modality. ${ }^{2,3)}$ Indeed, US is typically the only image used in evaluation of thyroid nodules; nearly all international guidelines for evaluation of thyroid nodules do not recommend use of other imaging studies, such as CT or MRI. ${ }^{2,4}$ However, US examination is highly operator-dependent and provides narrow-view images that are restricted to the region where the probe contacts; these cannot show anatomical relation-

This is an Open Access article distributed under the terms of the Creative Commons Attribution Non-Commercial License (https://creativecommons.org/licenses/by-nc/4.0) which permits unrestricted non-commercial use, distribution, and reproduction in any medium, provided the original work is properly cited. ships of the entire neck within the same view. In addition, because the thyroid gland neighbors and abuts many structures (e.g., strap muscle, trachea, esophagus, parathyroid gland, and recurrent laryngeal nerve), perithyroidal pathologies arising from those structures may mimic thyroid pathologies when viewed with US alone.

Bronchogenic cysts are small, solitary cysts or sinuses that are formed from an abnormal budding of the tracheal diverticulum in the 16 th week of gestation. ${ }^{5,6)}$ They are typically located in the mediastinum of pediatric patients, but may occasionally be found around the lower pole of the thyroid gland or level VI region, even in adults, during thyroid US ${ }^{5-7)}$ However, US findings of cervical bronchogenic cyst have not yet been reported; thus, preoperative diagnosis is quite challenging, and may lead to unnecessary diagnostic surgery.

In these case reports, we describe US findings of bronchogenic cyst that may mimic papillary thyroid carcinoma and 
introduce some sources of diagnostic error, with the aim of improved understanding of cervical bronchogenic cyst, as well as avoidance of misdiagnosis as suspicious thyroid nodule.

\section{Case}

The US systems used in these cases study were the HS 70A (Samsung Medison, Seoul, Korea) and the HD7 (Philips Healthcare, Bothell, WA, USA), each with a high-frequency linear transducer (3-12 MHz). Both patients underwent contrast-enhanced CT with a slice thickness of $3.0 \mathrm{~mm}$. The US findings were compared with $\mathrm{CT}$ findings and clinical records were reviewed for each patient.

\section{Case I}

A 29-year-old female visited our clinic for further evaluation of a thyroid nodule detected on thyroid US during a wellness examination. She complained of a mild foreign body sensation in throat, but the symptom was not considered associated with the nodule. On US, an ill-defined hypoechoic nodule was identified at the inferior pole of the right thyroid gland. The nodule had several internal echogenic foci resembling microcalcification; posterior extrathyroidal extension was suspected (Fig. 1A). On longitudinal US view, several arc-shaped hyperechoic lines were present at the peripheral portion of the nodule (Fig. 1B). According to the sonographic patterns in the American Thyroid Association (ATA) guidelines, as well as several thyroid imaging reporting and data systems (TIRADS), the nodule was classified as highly suspicious; thus, FNAC was performed. ${ }^{2,8)}$ The nodule was categorized as benign; however, it showed numerous ciliated co- lumnar epithelial cells rather than follicular cells. With these findings, we speculated that the lesion may have arisen from the respiratory tract; thus, we performed CT to characterize the anatomical relationship between the lesion and aerodigestive tract. The CT scan demonstrated an air-filled cyst at the posterior aspect of the right thyroid gland, which involved lower cervical to mediastinal regions (Fig. 2). Based on the results of US, FNAC, and CT analyses, the lesion was confirmed as a bronchogenic cyst. Because the patient had no symptoms related to the bronchogenic cyst, we recommended close observation with regular follow-up. For 35 months of follow-up, the lesion has remained stationary and the patient has not exhibited any complications.

\section{Case 2}

A 52-year-old female was transferred to our clinic for further evaluation of a thyroid nodule detected during a previous thyroid US. At the time of presentation, her chief complaint was mild odynophagia; laryngoscopic examination was unremarkable, with the exception of findings that indicated laryngopharyngeal reflux disease. On US, an ill-defined hypoechoic nodule was found at the inferior pole of the right thyroid gland (Fig. 3A) and right level VI region (Fig. 3B); it exhibited several internal echogenic foci mimicking calcification. According to the sonographic patterns of the ATA guidelines, as well as several TIRADS, thyroid cancer with central metastasis was included in the differential diagnosis. ${ }^{2,8)}$ However, considering our previous experience with a bronchogenic cyst, we recommended a CT scan prior to FNAC. On CT scan, several air-filled cysts were found, extending from the inferior pole of the right thyroid gland to
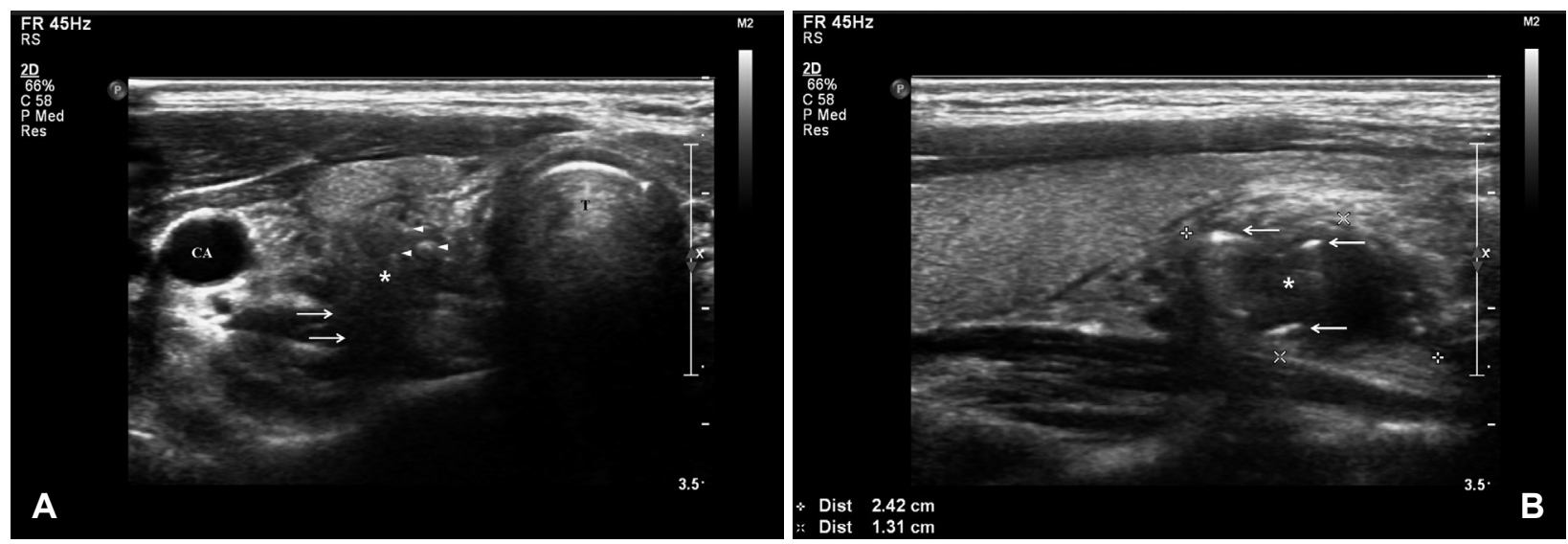

Fig. 1. III-defined hypoechoic nodule (asterisks) was identified at the inferior pole of the right thyroid gland. It exhibited several internal echogenic foci resembling microcalcification (arrowheads); posterior extrathyroidal extension (arrows) was suspected (A). On longitudinal ultrasound view, several arc-shaped echogenic lines (arrows) were also present at the peripheral area of the nodule (B). CA: carotid artery, T: trachea. 
the upper mediastinum (Fig. 4). There was no evidence of a suspicious thyroid nodule with calcification or central metastasis. Based on these findings, the lesion was diagnosed as a bronchogenic cyst. Because the patient had no symptoms related to the bronchogenic cyst, we recommended close observation with regular follow-up. For 30 months of followup, the lesion has remained stationary and the patient has not exhibited any complications.

\section{Discussion}

A bronchogenic cyst is a rare congenital anomaly formed by abnormal budding of the tracheal diverticulum; it is typically located in the mediastinum, most often in pediatric patients. ${ }^{5,6)}$ When it is located in the cervical region in adults, it is rarely diagnosed on preoperative US, due to its rarity and poor understanding of its US findings. Although there have been several reports of cervical bronchogenic cysts in adults, these were suspected to be thyroid tumor, parathyroid tumor, or brachial anomaly during initial preoperative evaluations; none were diagnosed without surgical intervention. ${ }^{5-7,9-11)}$ Fur-

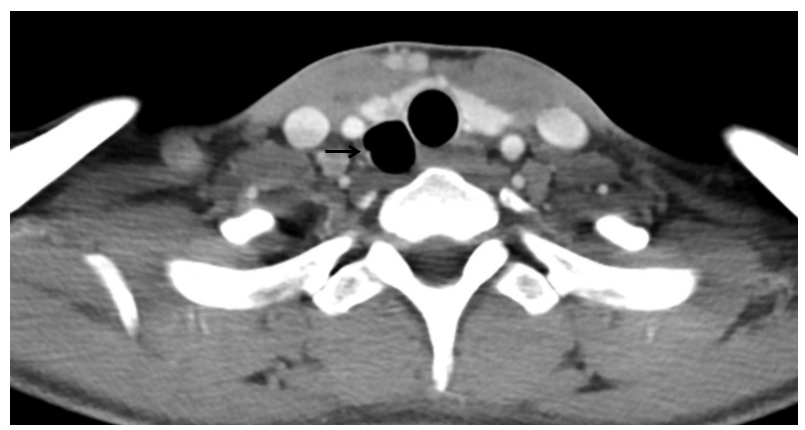

Fig. 2. CT scan shows a large air-filled cyst (arrow) at the posterior aspect of the right thyroid gland.

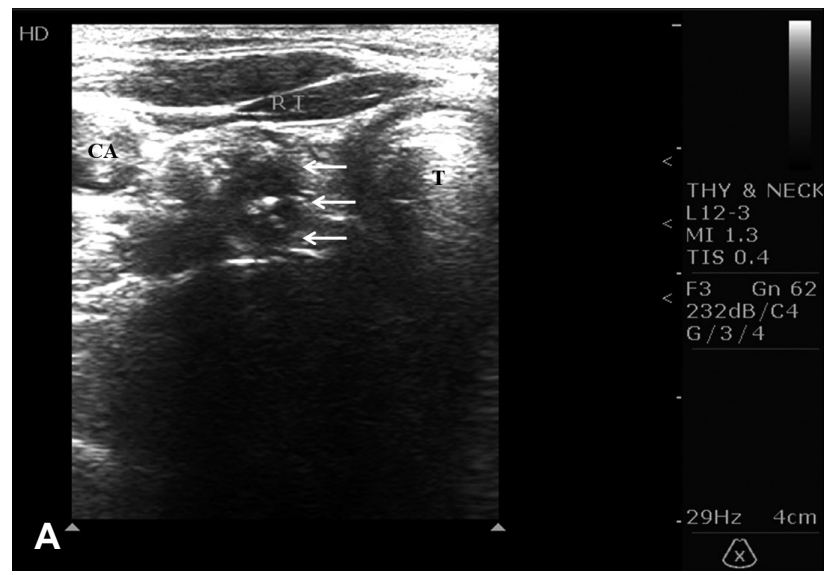

thermore, in most previous reports, US findings of bronchogenic cyst were not addressed.

In the two cases we have described, bronchogenic cysts appeared as ill-defined inhomogeneous hypoechoic nodules on US, exhibiting several echogenic foci or arc-shaped echogenic lines. Although these were designated as "cysts," their capsules were not distinct. The clinical significance of such cysts on thyroid US is that they can mimic thyroid cancer of the lower pole of the thyroid gland and/or its central metastases, due to their hypoechogenicity, unclear or irregular margin, and echogenic foci, which may be misidentified as microcalcification; these findings correspond to the typical findings of a highly suspicious thyroid nodule. ${ }^{2,8)}$

Several clues can be used to distinguish bronchogenic cysts from true thyroid malignancies. First, on US, echogenic foci or arc-shaped lines of the lesion do not exhibit clean acoustic shadowing, (i.e., a uniformly anechoic signal behind a structure) indicative of calcification; rather, they may demonstrate posterior reverberation and dirty acoustic shad-

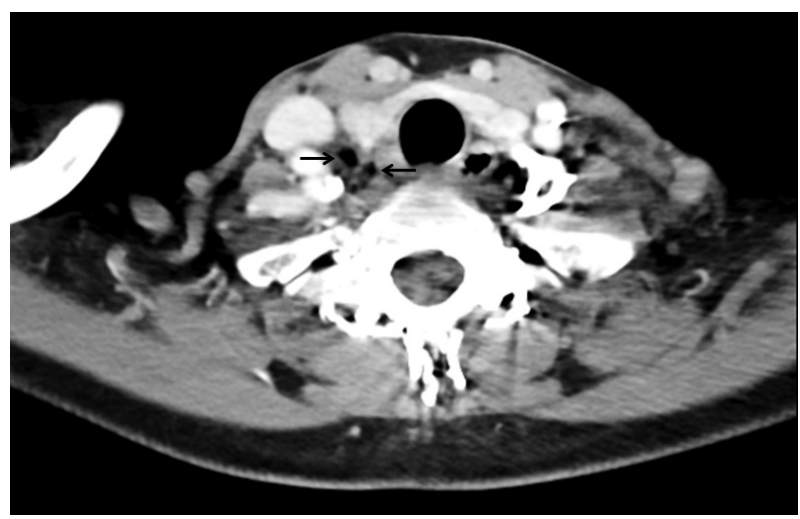

Fig. 4. On CT scan, several air-filled cysts (arrows) were identified at the inferior pole of the right thyroid gland.

Fig. 3. Ultrasound shows an ill-defined hypoechoic nodule (arrows) with several echogenic foci (arrowheads) at the inferior pole of the right thyroid gland $(A)$ and level VI region $(B)$. CA: carotid artery, T: trachea. 
owing (i.e., low-level echoes in the shadow, deep to air). ${ }^{12,13)}$ In addition, when needle aspiration is performed, the tactile sense of the needle is quite different from that of thyroid malignancy, because the internal contents of bronchogenic cysts constitute air without solid components; in contrast, these solid components are present in thyroid cancer. With respect to cytology, because bronchogenic cysts are lined by respiratory-type epithelium, which is characterized by cilia, FNAC can demonstrate ciliated columnar epithelial cells; these suggest that the lesion developed from the respiratory tract. However, obtaining an adequate specimen is often difficult, because this is an air-filled cyst composed of various fluids; therefore, preoperative diagnosis is difficult. Further, inappropriate FNAC can cause cyst rupture, pneumomediastinum, and secondary infection. Therefore, if a bronchogenic cyst is suspected on US, an additional CT scan can be helpful for diagnosis in that it demonstrates an air-filled cyst involving the lower cervical region around the thyroid gland; this may allow avoidance of unnecessary invasive procedures. However, confirmation of the diagnosis should be based on pathological examination demonstrating a cystic lesion lined with respiratory-type epithelium (ciliated columnar epithelial cells). ${ }^{10,11)}$

In addition to thyroid cancer, US findings of bronchogenic cyst can mimic those of esophageal diverticulum, which exhibits similar anatomical location and the presence of air, as in bronchogenic cysts. However, US findings of diverticulum involve changes in the shape and shadowing from microbubbles entering the diverticulum during swallowing, connection to the esophagus, a peripheral echogenic line, and a boundary hypoechoic zone. These findings facilitate differentiation of esophageal diverticulum from other disease entities. $^{14,15)}$

Regarding air-filled structures, such as bronchogenic cysts, the US could not clearly depict the margin of the lesion; thus, image discordance might be observed between the US and CT scans. This is an important limitation of the use of US images to examine air-filled structures. This phenomenon is regarded as a type of "dirty shadowing" artifact, which occurs as a results of the high degree of reflection at air-tissue interfaces. ${ }^{12,13)}$ Because the energy of a sound pulse reflected off air is similar that of the transmitted pulse, the reflected pulse will interact with interfaces in front of the air; this interaction produces secondary reflections, which travel back to the air surface and are reflected this surface back to the transducer. Notably, these secondary reflections produce low-lev- el echoes in the shadow deep to the air, thereby causing the "dirty" appearance. Consequently, structures posterior to the large air-filled structure cannot be depicted clearly by US, and may observed as distorted images that are not representative of the true anatomy. ${ }^{12,13)}$ US operator should recognize this phenomenon caused by dirty shadowing artifacts from air, in order to avoid misinterpretation of US images when examining air-filled lesions.

In conclusion, our cases showed that cervical bronchogenic cysts can present as highly suspicious thyroid nodules on thyroid US. However, recognition of this disease entity and comprehensive understanding of its presentation on US can facilitate appropriate diagnosis and avoid unnecessary diagnostic surgery.

\section{ORCID}

Dongbin Ahn

https://orcid.org/0000-0002-4977-7406

\section{REFERENCES}

1) Hoang JK, Lee WK, Lee M, Johnson D, Farrell S. US Features of thyroid malignancy: Pearls and pitfalls. Radiographics 2007;27(3): 847-60; discussion 861-5.

2) Haugen BR, Alexander EK, Bible KC, Doherty GM, Mandel SJ, Nikiforov YE, et al. 2015 American Thyroid Association management guidelines for adult patients with thyroid nodules and differentiated thyroid cancer: The American Thyroid Association Guidelines Task Force on thyroid nodules and differentiated thyroid cancer. Thyroid 2016;26(1):1-133.

3) Papini E, Guglielmi R, Bianchini A, Crescenzi A, Taccogna S, Nardi F, et al. Risk of malignancy in nonpalpable thyroid nodules: Predictive value of ultrasound and color-Doppler features. J Clin Endocrinol Metab 2002;87(5):1941-6.

4) Gharib H, Papini E, Paschke R, Duick DS, Valcavi R, Hegedüs L, et al. American Association of Clinical Endocrinologists, Associazione Medici Endocrinologi, and Europeanthyroid Association medical guidelines for clinical practice for the diagnosis and management of thyroid nodules. Endocr Pract 2010;16(Suppl 1):1-43.

5) Newkirk KA, Tassler AB, Krowiak EJ, Deeb ZE. Bronchogenic cysts of the neck in adults. Ann Otol Rhinol Laryngol 2004;113(9): 691-5.

6) Bocciolini C, Dall'olio D, Cunsolo E, Latini G, Gradoni P, Laudadio P. Cervical bronchogenic cyst: Asymptomatic neck mass in an adult male. Acta Otolaryngol 2006;126(5):553-6.

7) Barsotti P, Chatzimichalis A, Massard G, Wihlm JM. Cervical bronchogenic cyst mimicking thyroid adenoma. Eur J Cardiothorac Surg 1998;13(5):612-4.

8) Shin JH, Baek JH, Chung J, Ha EJ, Kim JH, Lee YH, et al. Ultrasonography diagnosis and imaging-based management of thyroid nodules: Revised Korean Society of Thyroid Radiology consensus statement and recommendations. Korean J Radiol 2016; 17(3):370-95.

9) Jun HH, Kim SM, Lee YS, Hong SW, Chang HS, Park CS. Cervical bronchogenic cysts mimic metastatic lymph nodes during thyroid cancer surgery. Ann Surg Treat Res 2014;86(5):227-31.

10) Lee JY, Lee JY, Jin SM, Lee SH. A case of bronchogenic cyst in the retropharyngeal space. Korean J Otolaryngol 2013;56(1):41-4.

11) Lee JD, Koh YW, Lee SW, Kim HK. A case of cervical bronchogenic cyst presenting as a thyroid tumor. Korean J Otolaryngol 2006;49 
(1):98-101.

12) Herring DS, Bjornton G. Physics, facts, and artifacts of diagnostic ultrasound. Semin Vet Med Surg (Small Anim) 1989;4(1):2-12.

13) Zdero R, Fenton PV, Bryant JT. Diagnostic ultrasound artifacts during imaging of two-body interfaces: Part 2--beam thickness artifact. Ultrasonics 2002;39(10):689-93.

14) Kwak JY, Kim EK. Sonographic findings of Zenker diverticula. J Ultrasound Med 2006;25(5):639-42.

15) Lixin J, Bing H, Zhigang W, Binghui Z. Sonographic diagnosis features of Zenker diverticulum. Eur J Radiol 2011;80(2):e13-9. 